\title{
Prenatal maternal conditioned fear and subsequent ulcer-proneness in the rat
}

\author{
R. W. BELL, G. H. HENDRY AND C. E. MILLER \\ NORTHERN ILLINOIS UNIVERSITY
}

Increased ulceration under immobilization stress was observed in rats which had been subjected to prenatal maternal fear conditioning coincident with the development of the fetal gut. Presentation of the CS (Buzzer) or UCS (Shock) alone did not affect ulceration, nor did the conditioning procedure if it occurred after the fetal gut development was complete.

Prenatal stress, chemical or environmental, can modify offspring, both structurally (e.g., Thompson \& Goldenberg, 1962) and behaviorally (e.g., Thompson, 1957), with the timing of the stress being an Important variable (e.g., Hartel \& Hartel, 1960). Montagu (1962, p. 201) has suggested that the effect (e.g., ulcers) of mild prenatal stress, such as maternal emotionality, may appear only under appropriate environmental conditions. Bell, Drucker, \& Woodruff (1965) found that prenatal injections of adrenalin increased the offspring's tendency to develop ulcers under immoblization stress if the injection occurred coincident with fetal gut development. Adrenalin injections after completion of fetal gut development did not significantly affect ulceration. It is hypothesized that the injections of adrenalin produced hormonal reactions in the pregnant rat similar to those produced by strong emotional states, and that increased ulceration under stress can be produced by maternal fear conditioning at the time the fetal gut is developing. Subjects

Twenty litters of Long-Evans Hooded rats, totaling 121 individuals, served as Ss.

\section{Apparatus}

The conditioning apparatus was a two-compartment shuttle box, constructed of white Marlite with a grid floor. Each compartment measured 15 in. $x 13$ in. $x 16$ in. high. Separating the two compartments was a 3 in. barrier and a vertically-opening door, which was operated by a motor and electro-magnet mounted on top of the apparatus. The grid floor was activated by a LVE 1531 shock-scrambler. Three Sylvania PCK-10 photoconductors were mounted in the wall on either side of the barrier to detect S's response and control the door closing and offset of CS (Buzzer) and UCS (1 mA shock).

\section{Experimental Design and Procedure}

The experimental design was a 5 by 2 factorial design, in which five prenatal treatments were administered at either of two periods of pregnancy. Four adult primiparous female rats were assigned to each of five treatment conditions. Half of each group received the treatment from the seventh through 10th day post-conception, when the fetal gut is developing, with the remaining Ss receiving the treatmont after the 10th day of gestation, after the fetal gut is developed. (Verifying the timing of treatment by counting back from parturition, it was discovered that Ss in Group 2, CS-UCS Experimental, actually received the treatment from 4 to 7 days and 8 to 11 days after conception. Timing of the treatment for all other groups was as intended.)

The five types of prenatal treatments were:

(1) CS Experimental: Maternal Ss received 20 trials per day for four (4) days of Buzzer-Shock avoidance conditioning. CS-UCS interval was 5 sec. The UCS intensity was $1.0 \mathrm{~mA}$. The required response was to jump over the barrier separating the two compartments of the shuttle box. Following conditioning, Ss were mated. During pregnancy Ss were again given 20 trials per day for four days in the shuttle box. However, only the CS(Buzzer) was activated during these trials, with no UCS (Shock) present at any time.

(2) CS-UCS Experimental: Maternal Ss were first mated, then received four days of avoidance conditioning at the appropriate period during pregnancy comparable to that experienced by Group 1 prior to mating.

(3) UCS Controls: Ss were first mated, then received a pattern of electric shock in the shuttle box comparable to that experienced by Group 2. No CS was present, nor was an escape or avoidance response possible. This group served to control for the possible effects of electric shock per se, and could be characterized as an unavoidable shock group.

(4) CS Control: Maternal Ss were first mated, then received a pattern of CS (Buzzer) presentations comparable to that experienced by Group 2. No UCS was presented, nor was an escape or avoidance response possible. This group served to control for possible reactions to the buzzer per se, which might have mild aversive properties.

(5) Apparatus Control: Maternal Ss were first mated, then were placed in the shuttle box for a period of time comparable to the other groups. This group served to control for possible effects of removal from the home cage to the shuttle box.

Following parturition, offspring were reared under standard laboratory conditions until 46 days of age. At that time, Ss were immobilized for $48 \mathrm{~h}$ by wrapping them in gauze and taping them to a board. This effectively prevented any movement other than slight head movements. During this time they were also food and water deprived. (See Sines, 1959, for a de- 
Table 1 Means, sample sizes, standard errors and summary of significant differences between means

\begin{tabular}{|c|c|c|c|c|}
\hline Source & df & M.S. & $\mathbf{F}$ & \\
\hline Between Groups & 9 & 51.05 & 5.23 & $p<.01$ \\
\hline Within Groups & 111 & 9.76 & & \\
\hline Treatment & $\begin{array}{c}\text { Time of } \\
\text { Treatment* }\end{array}$ & $\mathbf{n}$ & $\overline{\mathbf{x}}_{\mathbf{i}}$ & S.E. diff. \\
\hline \multirow[t]{2}{*}{ CS Exp. } & $7-10$ & 13 & $6.23^{* *}$ & 1.58 \\
\hline & $11-14$ & 12 & 1.67 & 1.62 \\
\hline \multirow[t]{2}{*}{ CS-UCS Exp. } & 47 & 18 & $4.33^{* *}$ & 1.45 \\
\hline & $8-11$ & 15 & $6.27 * *$ & 1.52 \\
\hline \multirow[t]{2}{*}{ UCS Cont. } & $7-10$ & 9 & 1.00 & 1.75 \\
\hline & $11-14$ & 14 & 2.36 & 1.55 \\
\hline \multirow[t]{2}{*}{ cs Cont. } & $7-10$ & 13 & 2.08 & 1.58 \\
\hline & $11-14$ & 8 & 2.62 & 1.82 \\
\hline \multirow[t]{2}{*}{ App. Cont. } & $7-10$ & 9 & 1.22 & \\
\hline & $11-14$ & 10 & 1.20 & \\
\hline
\end{tabular}

*Number of days after conception

**Significantly different from control groups at .05 level

tailed treatment of procedures and effects of immobilization.) Following immobilization, Ss were sacrificed, the stomach and duodenum removed, and the numizer of uicers (if any) tabulated.

Results

Since the timing of the prenatal treatment for Ss in Group 2 was not consistent with the timing of treatment for Ss in the other groups, the number of ulcers per $\mathbf{S}$ was analyzed as a one-way analysis of variance (Table 1), rather than a 5 by 2 factorial. Between groups variance was significant at the .01 level. Following the analysis, each group was compared against the apparatus control group (both sub-groups combined), using Dunnett's (1955) procedure. Ss in Groups 1 and 2 which received the conditioning procedure at the time the fetal gut was developing had a significantly higher mean number of ulcers than did Control Ss. The UCS Controls and CS Controls did not differ from the Apparatus Controls, nor did the CS Experimental Ss who were given the CS presentation after the fetal gut had developed (Table 1). Based upon analyses of variances, the three groups which did differ from the control group did not differ among themselves $(F=1.08, d f=2 / 43)$, nor did the other seven groups differ among themselves $(F=0.70$, df $=6 / 68$ ).

\section{Discussion}

It is apparent that presentation of an aversive stimulus during pregnancy does not, by itself, significantly influence the offspring's tendency to develop ulcers under stress. The unavoidable shock and unavoidable buzzer groups did not differ from the controls. Presenting a stimulus paired with aversive stimulation, or a stimulus which has previously been paired with aversive stimulation, does produce significant increases in ulcer-proneness. The use of an avoidance conditioning paradigm to produce the prenatal maternal emotionality is based upon an interpretation of avoidance responses developing from a conditioned emotional response, which serves as the drive for the avoidance response, and is consistent with Thompson's (1957) procedures.

The lack of an appropriate control for the timing of the prenatal treatment for Group 2 Ss prevents an unequivocal statement concerning the importance of the stage of prenatal development in producing increased susceptibility to ulceration as a function of prenatal maternal emotionality. The pattern of means for Group 1 does support the critical period hypothesis, as do data previously reported (Bell et al, 1965).

The present data suggest that psychophysiological breakdown under stress may be linked to specific trauma modifying prenatal development of structures. The specific mechanisms involved, the species-generality of the findings, and other types of psychophysiological reactions to stress which may be affected by prenatal trauma are, at present, unanswered questions. Such questions do pose interesting problems for future research, and suggest an approach to understanding individual differences in type of reaction to stress.

\section{References}

BELL, R. W., DRUCKER, R. R., \& WOODRUFF, A. B. The effects of prenatal injection of adrenalin chloride and d-amphetamine sulfate on subsequent emotionality and ulcer-proneness of offspring. Psychon. Sci, 1965, 2, 269-270.

DUNNETT, C. W. A multiple comparison procedure for comparing several treatments with a control. J. Amer. Statist. Assoc., 1955, 50, 1096-1121.

HARTEL, A., \& HARTEL, G. Experimental study of teratogenic effect of emotional stress in rats. Science, 1960, 132, 1483-1484.

MONTAGU, A. Prenatal influences. Springfield, Ill.: Charles C. Thomas, 1962.

SINES, J. O. Selective breeding for development of stomach lesions following stress in the rat.J. comp. physiol. Psychol, 1959, 52, 615-617.

THOMPSON, W. D. Influence of prenatal maternal anxiety on emotionality in young rats. Science, 1957, 125, 698-699.

THOMPSON, W. R., \& GOLDENBERG, L. Some physiological effects of maternal adrenalin injection during pregnancy in rat offspring.Psychol Rep., 1962, 10, 759-774.

Note

1. This work was supported in part by NIMH Grant 13057-01 MSM. 